\title{
O BEBÊ E A DOCÊNCIA NA CRECHE: contribuições da formação dialógica
}

\author{
Celi da Costa Silva Bahia? \\ Solange Mochiutti2
}

\section{RESUMO}

O conhecimento sobre a aprendizagem e o desenvolvimento do bebê em ambientes coletivos e o trabalho docente com/para eles, é crescente. Contudo, poucos docentes que têm acesso a esta produção. Sem negar a importância dos saberes produzidos na relação com os bebês, é necessário oportunizar aos professores o acesso ao conhecimento produzido sobre a docência na primeiríssima infância. A formação dialógica se apresenta como possibilidade de valorização desses saberes em articulação com os conhecimentos produzidos cientificamente. O estudo objetiva analisar a contribuição da formação dialógica para mobilizar transformações na rotina da creche. A pesquisa foi de natureza qualitativa e utilizou como informação o registro reflexivo de professoras integrantes do projeto "formação continuada de professoras de berçário: as vozes das professoras na construção de saberes sobre a docência com bebês". Os resultados revelaram que o processo formativo permeado pela ação e reflexão, para além do domínio de conhecimentos ou de conteúdo, colaborou com a construção de posicionamento reflexivo que se traduziu em ações e relações interpessoais, o que exigiu das professoras ultrapassar a si mesma e colocar-se em direção ao outro, seja ele o bebê ou o adulto, em busca da superação de limites e a construção de outras possibilidades de ser docente de bebês; apontam também para a necessidade de trabalhar na construção de práticas de formação que assegurem espaços, de articulação dos saberes dos professores com o conhecimento científico. A formação dialógica, enquanto ato coletivo, permeado pelo diálogo permite ao professor encantar-se com sua prática e motivar-se para mudanças necessárias na creche.

Palavras-chave: Formação dialógica. Bebê. Docência na creche.

1 Doutora em Teoria e Pesquisa do Comportamento Humano pela Universidade Federal do
Pará (UFPA); Professora no Curso de Pedagogia do Instituto de Ciências da Educação da
UFPA - Brasil; Coordenadora geral do Grupo IPE e diretora da Faculdade de Educação/
ICED/UFPA. Orcid iD: https://orcid.org/0000-0002-3104-2647. E-mail: celibahia@yahoo.com.br
2 Mestrado em Educação pela Universidade Federal do Pará; Professora aposentada da
Escola de Aplicação da Universidade Federal do Pará (EA-UFPA) - Brasil; Integra o Grupo de
Estudos e Pesquisas em Criança, Infância e Educação Infantil (IPE), do Instituto de Educação
$\begin{array}{llll}\text { (ICED/UFPA). } & \text { Orcid } & \text { iD: https://orcid.org/0000-0002-5085-0260. }\end{array}$ solange.mochiutti@gmail.com 


\title{
THE BABY AND THE TEACHING AT DAY CARE: contributes of dialogical
}

\section{formation}

\begin{abstract}
The knowledge about the baby's learning and development in collective environments and the teaching work with/for them is growing. However, few teachers who have access to this production. Without denying the importance of knowledge produced in the relationship with babies, it is necessary to provide to the teachers the access to the knowledge produced about teaching in very early childhood. The dialogical formation introduces itself as a possibility of value these knowledges in articulation with the scientifically produced knowledges. The study objectives is to analyze the contribution of dialogical formation to mobilize changes at day care routine. The research was of qualitative nature and used as information the reflective record of teachers participating of the project "Continuing education of early years teachers: teachers' voices in the construction of knowledge about teaching with babies". The results revealed that the training process permeated by action and reflection, in addition to the domain of knowledges or content, collaborated with the construction of reflective positioning that translated into actions and interpersonal relationships, what required of teachers to go beyond themselves and place themselves towards the other, be it the baby or the adult, in search of overcoming limits and the construction of other possibilities of being a teacher of babies; they also point to the need of working on the construction of training practices that ensure spaces of articulation of teachers' knowledge with scientific knowledge. Dialogic formation, as a collective act, permeated by dialogue, allows teachers to be enchanted with their own practice and motivate themselves to make necessary changes at day care.
\end{abstract}

Keywords: Dialogical formation. Baby. Teaching at day care.

\section{EL BEBÉ Y LA DOCUMENTACIÓN EN LA CASA DE NIÑOS: aportaciones de la formación dialógica}

\section{RESUMEN}

Los conocimientos sobre el aprendizaje y el desarrollo del bebé en entornos colectivos y el trabajo pedagógico con/para ellos, son cada vez mayores. Sin embargo, pocos profesores tienen acceso a esta producción. Sin negar la importancia del conocimiento producido en la relación con los bebés, es necesario dar a los profesores la oportunidad de acceder al conocimiento producido sobre la enseñanza en la primera infancia. La formación dialógica se presenta como una posibilidad de valorización de este conocimiento en articulación con el conocimiento científicamente producido. El estudio pretende analizar la contribución de la formación dialógica para movilizar las transformaciones en la rutina de la guardería. La investigación fue de carácter cualitativo y utilizó como información el registro reflexivo de las maestras integrantes del proyecto "formación continua de las maestras de párvulos: las voces de las maestras en la construcción 
del conocimiento sobre la enseñanza con bebés". Los resultados revelaron que el proceso formativo permeado por la acción y la reflexión, más allá del dominio de los conocimientos o contenidos, colaboró con la construcción de un posicionamiento reflexivo que se tradujo en acciones y relaciones interpersonales, lo que exigió de las maestras ir más allá de sí mismas y avanzar hacia el otro, sea el bebé o el adulto, en busca de la superación de los límites y la construcción de otras posibilidades de ser maestras de bebés; también señalan la necesidad de trabajar en la construcción de prácticas formativas que aseguren espacios para la articulación del conocimiento de las maestras con el conocimiento científico. La formación dialógica, como acto colectivo, impregnada de diálogo, permite que los profesores estén encantados con su práctica y se sientan motivados para realizar los cambios necesarios en las guarderías.

Palabras clave: Formación dialógica. Bebé. Enseñanza en guarderías.

\section{INTRODUÇÃO}

Sabe-se que nos últimos anos, grande parte dos bebês estão vivendo o tempo da infância em ambientes coletivos, seja em decorrência das mudanças na organização familiar, bem como em virtude da produção do conhecimento sobre o desenvolvimento do bebê. De acordo com dados do INEP (2017) no período de 2011 a 2016, as matrículas em creche cresceram $56,6 \%$. Esta foi a etapa de ensino que teve maior crescimento no número de matrículas da educação básica. Apesar deste crescimento, dados do relatório do segundo ciclo de monitoramento das metas do Plano Nacional de Educação - 2018 revelam que em 2016, apenas 32\% das crianças de zero a três anos frequentavam a creche, o que representa 3,4 milhões de crianças, isso significa que em torno de 7,5 milhões de crianças estavam fora da creche. Ressalta-se que mesmo com a expansão observada, a creche apresenta maior demanda, por ser o segmento que apresenta a mais baixa cobertura (PNAD, 2016). Esses dados evidenciam a relevância de maiores esforços para que a creche, de fato, se transforme em espaço de desenvolvimento dos pequeninos.

Para que a creche se torne contexto de desenvolvimento o caminho é longo e precisa ser assumido por todos aqueles que direta ou indiretamente trabalham com os bebês. Neste prisma, sem negar outros fatores que influenciam no trabalho desenvolvido pela creche, destaca-se a 
importância da formação ${ }^{3}$ do professor que cotidianamente estabelece relações com os pequeninos.

Nas últimas décadas, é crescente a produção do conhecimento sobre o bebê em diversas áreas, entre estas, a Pedagogia, com seus estudos sobre o processo de aprendizagem e desenvolvimento do bebê em ambientes coletivos e o trabalho docente com e para eles. Entretanto, muito ainda é necessário aprender para que a creche se efetive como espaço para $\circ$ desenvolvimento de bebês.

Nesse sentido, o debate dirige-se para a socialização do conhecimento produzido com os que estabelecem relações diariamente com os bebês, pois este nem sempre chega até o professor. Ainda que se destaque a necessidade dessa socialização, não se pode negar que na relação com os pequeninos os professores também produzam conhecimentos, os quais precisam ser valorizados.

Essa compreensão chama para o debate sobre os modelos de formação inicial e continuada do professor que exerce a docência na creche. Por diversas razões, o currículo dos cursos de Pedagogia, bem como a formação continuada do professor não têm conseguido assegurar ao professor uma sólida formação teórico prática a partir da especificidade do bebê e da docência com e para ele.

Com a perspectiva de acrescentar subsídios à superação de modelos de formação em que os conhecimentos científicos ocupam centralidade e minimizam o saber próprio da profissão de ensinar, os quais são construídos nas interações estabelecidas pelos professores, intenciona-se neste trabalho analisar a contribuição da formação dialógica de professores para mobilizar transformações na rotina da creche.

Os dados foram produzidos a partir de informações coletadas durante o desenvolvimeLnto do projeto "Formação continuada de professores de berçário: as vozes das professoras na construção de saberes sobre a

\footnotetext{
3 Apesar de o foco da discussão deste artigo ser a formação do professor, não se pode negar que inúmeros fatores influenciam para que a creche se torne um espaço que assegure o desenvolvimento integral do bebê.
} 
docência com bebês", o qual se fundamentou nos estudos acerca da formação dialógica (GOULART, 2016), bem como nos estudos sobre o bebê e a docência com e para eles. O referido projeto foi desenvolvido com professoras de Berçário da rede pública do município de Belém. De acordo com as normas da secretaria de educação as turmas de Berçário são constituídas de 18 bebês e duas professoras. Nessa pesquisa, contou-se com a participação de 12 professoras integrantes do projeto acima mencionado.

\section{O BEBÊ E O TRABALHO DOCENTE COM E PARA ELE NO COTIDIANO DA CRECHE}

Historicamente $O$ bebê era visto como um ser marcado por características essencialmente biológicas, que necessita de cuidados para assegurar a sua sobrevivência. Sendo um ser biológico, as ações a eles destinadas estão direcionadas para 0 atendimento das necessidades básicas como higiene, saúde e nutrição, cujas ações são realizadas em detrimento de atividades intelectuais. De acordo com Gottlieb (2009, p. 323), a maioria desses processos envolve a expulsão de substâncias que são desvalorizadas na sociedade ocidental, como lágrimas, urina, fezes, vômito.

Nessa perspectiva, para Gottlieb (2009), o bebê ocupa o lugar do não sujeito na sociedade. Assim, o foco reside na negatividade, ou seja, naquilo que ele ainda não é capaz de realizar. A referida autora chama atenção para o lugar que os bebês ocupam nas sociedades ocidentais, pois estas definem os processos racionais com base nas capacidades intelectuais - a habilidade de se comunicar por meio da fala, de construir redes sociais complexas, de organizar o mundo à sua volta, de planejar o futuro - e questiona o que sobra para os bebês - aparentemente especializados em processos mais primitivos como comer, dormir e fazer suas necessidades fisiológicas - ou seja, os bebês aparentam criaturas mais dependentes e apresentam menos iniciativa entre os humanos.

Corroborando com esse raciocínio, Barbosa e Fochi (2012) destacam que a criança é vista de forma negativa, como um ser que ainda não é, não fala, não anda, não sabe, não entende. Marcados pela falta e pelas especificidades de sua condição enquanto bebês, eles se tornaram invisíveis 
em suas competências. Isso significa que necessário se faz construir novos olhares para os pequeninos. Em lugar da falta, necessidade, fragilidade, desproteção, que marcam as relações com os bebês sobre o viés da disciplina, do higienismo e do controle, é necessário compreender que a imaturidade característica dos bebês "não é impotência, senão possibilidades e potencialidades de crescer" (BARBOSA; FOCHI, 2012, p. 5).

Ao compreender a impotência do bebê como possibilidades e potencialidades de crescer, Barbosa e Fochi (2012) apontam para a necessidade de se romper com relações que consideram os bebês pela falta e argumentam que o fato de o bebê não falar ou andar não quer dizer que ele necessita apenas ser cuidado, alimentado e higienizado. Por isso, há a necessidade de olhar para o bebê como ser potente e em sua inteireza, como sujeito protagonista de suas aprendizagens, com iniciativas, interesses e sentimentos. Para tanto, convém compreender que as formas utilizadas pelos bebês para interpretar, significar e comunicar são oriundas do corpo e acontecem por meio dos gestos, dos olhares, dos sorrisos, dos choros, enquanto movimentos expressivos e comunicativos anteriores à linguagem verbal.

Esse olhar permite a construção de lógicas de interação a partir do modo próprio com que o bebê atua com e sobre o mundo enquanto sujeitos legítimos, produtores ativos de cultura (GOTTLIEB, 2009), portanto, seres de linguagens, que ativamente participam de processos interativos, como acentuam Barbosa e Richter (2010).

Então, quando se pensa em educação de bebês na creche, esta precisa ser planejada com e para eles, isso é, a partir do que ele comunica por meio do seu corpo, de suas necessidades e interesses. Essa perspectiva tem exigido dos adultos a compreensão de que os bebês sabem muitas coisas que nós culturalmente não conseguimos ainda ver e nem tão pouco compreender (BARBOSA; RICHTER, 2010). Portanto, os adultos têm muito a aprender sobre esse ser chegante no mundo e que apresenta formas tão peculiares de nele viver, bem como apresenta outras lógicas de interação, a partir daquilo que lhe é próprio. Tendo como referencial seu corpo, o bebê 
manifesta-se por meio de choros, risos, toques, olhares, mordidas, o que permite a interação dele com as pessoas e com o meio no qual ela está inserida. Nesse processo, o bebê deixa suas marcas e constrói sua personalidade, bem como "nos ensina sobre como eles são e sobre como vivem suas primeiras experiências de vida" (CASTELLI; MOTA, 2013, p. 3).

A percepção que se tem sobre o bebê, seja como ser biológico, seja como ser social, articula-se com o trabalho da creche. Ao considerar o bebê um ser biológico, o trabalho na creche se organiza sob uma ótica autocêntrica, com rotinas rígidas, tendo por referência a funcionalidade da instituição. Com foco no cuidado do corpo, a preocupação central é a segurança física da criança, o que termina por justificar certo "isolamento" dos bebês em um único espaço.

Do ponto de vista acima descrito, as relações são verticalizadas e mecânicas, sem haver lugar para o olhar, o toque, nem tão pouco para dar sentido às manifestações do bebê. Os momentos de cuidado, ainda que ocupem grande parte do tempo na instituição, são considerados de menor valor, razão pela qual são cada vez mais abreviados de modo a garantir o funcionamento da rotina na instituição. Em oposição ao cuidado, atividades dirigidas são consideradas mais nobres e precisam ter tempo e espaço assegurado. Nesse processo, o bebê transforma-se em um objeto nas mãos de quem o cuida e, consequentemente, o bebê nunca tem tempo para manifestar seus pensamentos, desejos, necessidades e etc. Assim, as sutilezas inerentes as relações humanas passam despercebidas.

Por sua vez, a visão de bebê enquanto ser social nos coloca diante da necessidade de compreender que o trabalho na creche vai além do simples cuidado, pois o que está em jogo é a formação da identidade individual e coletiva dos pequeninos, como assinalam Barbosa e Guimarães (2009, p. 52): "trata-se de considerar o espaço da creche como oportuno para a formação da identidade, a constituição do eu no contato com o social, entendendo que o conhecimento de mundo acontece imbricado no conhecimento de si". 
O reconhecimento do bebê enquanto ser social aponta para a centralidade das relações estabelecidas no processo de aprendizagem e desenvolvimento deles. Por essa razão, é fundamental outra lógica de organização para a creche. Assim, as rotinas rígidas e marcadas por relações em que o adulto é o centro do processo, precisam ceder lugar a uma organização que possibilite tempo e espaço para o bebê se relacionar com os adultos e com as crianças que frequentam a instituição. Nesse sentido, o espaço para o bebê estar na creche são todos os lugares da instituição que favorecem o encontro dos pequeninos com o que há no interior e exterior da creche (pessoas, espaços diversos, odores, cores, formas, etc).

As pesquisas de Sabbag (2017) e Silva (2018) confirmaram o corpo como um elemento central nas relações docentes na Educação Infantil. A relação corporal é intensa, em especial, na docência com bebês, pois os bebês se comunicam, sobretudo, com o seu corpo. Para tanto é indispensável que as professoras atentem para a dimensão corporal, tornando essa relação menos verticalizada, enxergando os bebês para além do corpo físico que requer cuidado. A dimensão do cuidado, desta forma, vai além de ações mecanizadas, entendendo o cuidado para além dos momentos de higiene e alimentação. Sabbag (2017), destaca que é preciso evidenciar essas ações como potência, pois são momentos ricos de encontros e trocas, fundamentais para o processo de socialização e constituição dos bebês. Portanto, são ações que consolidam a relação com o outro, relação essa que constitui a docência com e para os bebês

Em virtude da centralidade das relações na educação dos bebês, ainda que a creche seja uma instituição coletiva, ela precisa se organizar para assegurar relações individualizadas, personalizadas que considerem as singularidades de cada bebê em sua completude humana. Neste sentido, ainda que na cultura da creche as situações de cuidado sejam consideradas com menor importância, Duarte (2012) destaca que essas têm centralidade na creche, pois são momentos ricos de interação entre o bebê e o adulto que o cuida. As situações de cuidado possibilitam o contato 
direto do adulto com o bebê e neste o bebê manifesta seus desejos, sentimentos e emoções por meio do seu corpo, como troca de olhares, sorrisos, balbucios, ou ainda pelo ato de apontar, tocar, entre outros.

O reconhecimento de que, mesmo não dominando a linguagem oral, o bebê se comunica por meio do seu corpo, ratifica o quanto a proximidade física entre o adulto e o bebê é fundamental para que este possa se comunicar. Dessa forma, destacam-se as contribuições de Hevesi (2004), ao afirmar que, quando o adulto segura um bebê, é possível notar o relaxamento ou tensão de seus músculos demonstrando satisfação ou incômodo com o toque em seu corpo.

Ainda que se enfatize a competência do bebê para comunicar seus pensamentos, sentimentos, desejos, emoções e necessidade, ressalta-se a necessidade de sensibilidade por parte do adulto que com ele interage para perceber a singularidade na forma de comunicação do bebê e responderIhe adequadamente. Sendo assim, sensibilidade para estar com os bebês é condição para reconhecer a competência e valorizar cada gesto dos pequeninos, pois nas respostas do adulto para o bebê ele vive a experiência da competência e, consequentemente, constrói sentimentos de segurança que são a base de sua personalidade.

Hevesi (2004), ao reconhecer a competência comunicativa do bebê, acentua que ele coopera, logo, apresenta competência para participar da ação que é realizada em seu corpo, mas suas respostas demandam tempo para que receba e compreenda a situação e, em seguida, responda ao adulto com quem interage.

Portanto, Hevesi (2004) defende a necessidade de planejamento para garantir o tempo necessário para que o bebê coopere. O tempo é necessário para que o professor se organize para estar com o bebê nas diversas situações, mas particularmente nos momentos de cuidado, pois estes são os que ocupam a maior parte do tempo na instituição e possibilitam o contato individual do adulto com o bebê (DUARTE, 2012). Quando há planejamento, enquanto o docente se direciona a um bebê, os demais podem ocupar-se da exploração de objetos ou estar com seus 
pares. Isso é muito importante, pois "para o bebê, ir à creche é ter a oportunidade de se relacionar, de ampliar suas experiências através do convívio com os outros" (DUARTE, 2012, p. 2).

A crescente produção do conhecimento acerca do bebê sobre seu processo de aprendizagem e desenvolvimento em ambientes coletivos e o trabalho docente com e para eles, apontam que, na docência com bebê, é indispensável um olhar sensível para o bebê enquanto um ser potente que se utiliza de formas de comunicação, as quais são distintas das formas utilizadas pelos adultos. Por essa razão, a formação do professor que exerce a docência com bebês é indispensável. Contudo, esta precisa valorizar os saberes construídos no cotidiano pelos professores nas relações que estabelecem com os bebês.

\section{SABERES DOCENTES E A FORMAÇÃO NA PERSPECTIVA DIALÓGICA}

A discussão da formação de professores nos remete à problematização dos modelos de formação predominantes. Nesses construtos, os conhecimentos científicos ocupam lugar central, implicando a minorização de um saber próprio da profissão de ensinar, construído nas interações que os professores estabelecem com outros atores, entre eles, os bebês que frequentam as turmas de Berçário. Por esse motivo, os professores que atuam nas instituições educativas têm encontrado pouco espaço para falarem sobre os saberes que constroem cotidianamente no enfrentamento com os desafios impostos pela docência.

Em oposição a esses modelos e entendendo o professor enquanto ator e profissional, Tardif (2002) advoga que, para se pensar a formação do professor, é necessário trabalhar na perspectiva de uma Epistemologia da prática profissional. Entende-se esta como o estudo do conjunto dos saberes, utilizados realmente pelos profissionais em seu espaço de trabalho cotidiano para desempenhar todas as suas tarefas (TARDIF, 2002). Argumenta o autor que os conhecimentos universitários nem sempre respondem às demandas da prática. Isso permite compreender que a prática não é espaço de aplicação de conhecimentos universitários. Muitas vezes, os apontamentos 
acadêmicos não têm relação com a realidade do trabalho docente diário nem com os contextos concretos de exercício da função docente.

Enquanto ator e profissional, o professor possui saberes e, no seu cotidiano, demonstra competências durante o trabalho que realiza. Para tanto, Tardif (2002) defende que a pesquisa universitária precisa buscar os saberes dos professores, a fim de compor um repertório de conhecimentos para a formação deles.

Reconhecer os saberes docentes como condição para se (re)pensar as práticas de formação de professores, que vêm sendo oferecidas na universidade, é focar na perspectiva de formação dialógica como possibilidade de formar professores e trazer para o debate os seus saberes.

Esse raciocínio se fundamenta na compreensão de que a formação docente é um processo contínuo e permanente, indicando que a docência, enquanto ato humano se constitui do seu inacabamento (FREIRE, 1996). Portanto, a formação docente não se limita a sequências lógicas em relação ao conhecimento científico, ao currículo e ao desenvolvimento das atividades pedagógicas. De acordo com Freire (1996), a formação é um ato contínuo que ocorre por meio da reflexão sobre a prática. Isso significa que a formação perpassa necessariamente pelo ato reflexivo do pensamento marcado pelo movimento de ação e reflexão, o qual articula a experiência acumulada no cotidiano da escola com concepções teóricas.

Nessa ótica, em oposição à formação limitada à aquisição de conteúdos a serem ensinados, Freire (1987) entende ser esta "um trabalho de reflexibilidade crítica sobre a prática de (re)construção permanente de uma identidade pessoal e profissional". Assim, a formação docente é entendida como um processo que ocorre por meio da reflexão sobre a prática pedagógica articulada aos saberes e às práticas acumuladas sobre a educação, bem como pela capacidade de mobilizá-los em um processo de construção interpessoal.

Para Goulart (2016), a reflexão sobre a prática docente é apreendida como um movimento de articulação ativa e interativa da capacidade discursiva, por envolver atos de rever, repensar, reorganizar e retomar ações. 
Representa um trabalho constante de ir e vir, construção e reconstrução de um processo dialógico, que envolve indagações a respeito desses saberes e das práticas apresentadas. Portanto, de acordo com a autora, essa atitude reflexiva envolve um diálogo consigo mesmo por criar um espaço de interlocução com outras vozes interiores, outras concepções, crenças e outros modos de compreender a prática docente que conosco dialoga.

Percebe-se que, na perspectiva de formação dialógica, o diálogo ocupa lugar central ao colocar o professor em uma atitude indagadora da própria prática. Assim, essa atitude de (re)pensar e (re)criar permeia o percurso formativo do professor (GOULART, 2016).

Nesse prisma, é no espaço da relação dialética entre o individual e o coletivo que se manifestam, por meio da ação reflexiva de diferentes vozes, as minúcias do cotidiano da instituição educativa. Na oralidade reflexiva, mediante os movimentos circulares e em constantes retomadas de posições, é possível entender a complexidade da vida vivida no coletivo da instituição e produzir momentos de rupturas para (re)pensar a prática docente, bem como construir saberes que colaboram para o desenvolvimento profissional dos professores. Em última instância, a reflexão é um convite para inverter a lógica das relações hierarquizadas tão presentes nos modelos formativos predominantes, ao mesmo tempo em que se constitui em uma possibilidade interessante para a investigação e formação.

Em face do exposto, entende-se ser o processo formativo do professor uma atividade na qual o pensamento e a ação, a teoria e a prática não se separam, ou seja, a formação é um processo artesanal, pois é um saber que se produz em um tempo e lugar. Razão pela qual se faz urgente superar práticas meramente técnicas, rotineiras e monótonas de formação que negam a possibilidade de pensar e de sentir, e, consequentemente, não se fazem relevantes à qualificação do fazer docente no sentido do prazer e da responsabilidade para com o trabalho bem feito. 


\section{METODOLOGIA}

A pesquisa realizada foi de natureza qualitativa e utilizou como fonte de informações para análise as reflexões decorrentes do trabalho desenvolvido no projeto "formação continuada de professoras de berçário: as vozes das professoras na construção de saberes sobre a docência com bebês", o qual tinha por objetivo documentar e ampliar os saberes das professoras sobre o bebê e o processo educativo deles em ambientes coletivos, bem como refletir sobre a docência com e para os bebês.

O referido projeto fundamentou-se na perspectiva dialógica de formação (GOULART, 2016) por considerá-la como possibilidade de recuperar os saberes docentes que vêm guiando a prática pedagógica na pequeníssima infância, bem como uma possibilidade de (re)significá-la. Estes fundamentos serviram de base para a tomada de decisões quanto aos procedimentos metodológicos a serem utilizados no desenvolvimento do projeto.

Para compor o grupo, a coordenação do projeto convidou as professoras que trabalham com crianças em idade inferior a dois anos de idade para participarem dos encontros de formação. Na oportunidade, explicitaram-se os objetivos e a metodologia de desenvolvimento do projeto. Condicionadas ao convite, as professoras tinham liberdade de aceitar ou não participar do projeto. Quando aceitavam, as professoras assumiam um compromisso com o seu processo formativo e com o grupo envolvido.

Após a organização do grupo, com 12 participantes, iniciaram-se os encontros com a participação de professoras de diferentes unidades educativas. Os encontros aconteciam uma vez por mês no espaço da Universidade Federal do Pará (UFPA). Em conformidade com os pressupostos da perspectiva dialógica de formação, as vozes das professoras e o registro reflexivo de suas práticas foram centrais no desenvolvimento do projeto. Assim, com a finalidade de incentivar a leitura dos textos e/ou observação da prática docente, bem como de conduzir o debate, ao final de cada encontro se deixava uma questão disparadora que daria início ao encontro subsequente. 
Para a seleção da questão disparadora, considerava-se a necessidade de desdobramentos, ampliação, aprofundamento e/ou esclarecimento acerca de determinada temática. Assim, estas emergiam do debate e não se esgotavam em um encontro. Quando o grupo visualizava a necessidade de ampliação de determinada temática, ainda que esta já tivesse sido discutida anteriormente, retomava-se o debate recuperando alguns conceitos e/ou concepções de modo articulado com a questão corrente ou resgatando a discussão no encontro subsequente. Dessa forma, a articulação entre os encontros permeou todo o processo formativo dos envolvidos.

Com vistas aos princípios da formação dialógica, as relações horizontais, marcadas pela reciprocidade e confiança, foram aspectos estruturantes dos encontros. Ainda que se tivessem pistas iniciais acerca do percurso a ser trilhado, o processo foi sendo tecido no encontro de professoras com e entre os participantes, por meio das narrativas que estes traziam para o debate sobre o bebê e o cotidiano da docência na creche. Essas narrativas eram gravadas, depois transcritas e analisadas pelos professores pesquisadores.

Paralelamente aos diálogos estabelecidos durante os encontros, as professoras foram convidadas a registrarem e refletirem sobre suas práticas, sendo estas fundamentadas nas ideias de autores que abordam o bebê e a docência com e para eles.

Com esse procedimento, as professoras traziam para os encontros seus saberes produzidos na e pela experiência enquanto docentes de bebês, bem como suas reflexões sobre o bebê e a prática docente que compartilham cotidianamente com eles. Desse modo, a reflexão sobre a prática permitiu a ampliação dos diálogos estabelecidos durante os encontros e estes, por sua vez, ampliavam a reflexão sobre a prática. Assim, ao tomar a reflexão sobre prática como eixo da formação docente, o ir e o vir marcaram o processo formativo das professoras de modo a valorizar seus saberes e, por fim, mobilizá-las na (re)construção destes. 
Assim, a pesquisa realizada utilizou, como fonte de informação o registro reflexivo de professoras integrantes do projeto. A escolha pelo registro reflexivo das professoras se justifica pelo fato de neles se encontrarem informações importantes sobre o tempo do bebê no cotidiano da creche.

\section{RESULTADO E DISCUSSÃO}

A fim de melhor entender a contribuição da formação dialógica de professores para mobilizar mudanças na rotina da creche, será apresentada a análise do registro reflexivo da prática de professoras participantes do projeto, os quais ajudam a visualizar os deslocamentos por elas realizados a partir do processo formativo.

Refletindo sobre minha prática percebo que estar com o bebê é estar atenta as suas ações e expressões em todos os momentos em que o professor está com o bebê com vistas a responder as necessidades e possibilidades que ele apresenta. Contudo, o que muito inquieta é o tempo da instituição educativa, organizado em função da rotina institucional. Este não se articula com o tempo destinado ao bebê, pois na rotina institucional não há tempo para o bebê se manifestar e nem tão pouco tempo para ouvi-lo, entendê-lo e menos ainda para esperar as suas respostas. Assim, o que se observa é um distanciamento entre o funcionamento da unidade educativa e o que é próprio da docência com bebês. O que temos ainda são espaços inadequados com rotinas rígidas e com uma razão adulto criança[sic] que dificulta o estabelecimento de relações, ou seja, rotinas que atrapalham a construção de práticas que respeite o tempo do bebê na instituição. Assim, o tempo de contato da professora com o bebê nas situações de cuidado, que é tão importante, é muito curto, o que termina gerando angústia e sentimento de estar trabalhando de maneira errada. Apesar das dificuldades decorrentes da rotina institucional, sempre me dirigi aos bebês com gestos delicados e de maneira amigável e acreditava que isso era suficiente e me sentia feliz por acreditar que estava fazendo o melhor e [sic] mais correto. O convite para ir ao banheiro, os breves diálogos durante o banho e pedir licença faziam parte da minha prática. Mas a leitura dos textos me fez perceber que não dava tempo para ouvir as respostas dos bebês, ou seja, não possibilitava a cooperação (HEVESI, 2004). Assim, minha prática era conduzida de tal modo que o bebê era obediente e submisso no espaço da instituição. Esta percepção me colocou diante do desafio de desacelerar o ritmo das atividades para que no tempo e espaço da instituição o bebê não fosse levado a aprender de modo mecânico, pois entendi o quanto isso é prejudicial para a formação deles enquanto sujeitos (registro PA).

Refletir sobre o tempo do bebê, me permitiu perceber que, apesar de conversar com o bebê, não espero o seu tempo. Minhas ações acompanham o ritmo das minhas palavras - ao mesmo tempo que

Revista Exitus, Santarém/PA, Vol. 12, p. 01 - 20, e022006, 2022. 
[sic] chamo a criança para o banho, minhas mãos agem sobre ela tirando-lhes as roupas. Assim, em nome de garantir o tempo da rotina da instituição, tudo é realizado de modo acelerado na instituição e não há tempo para o bebê. Durante anos de experiência como docente de bebê, esta prática nunca foi objeto de estranhamento na instituição, talvez em função da cultura da creche que sempre priorizou assegurar o cumprimento da rotina institucional. Compreender que o bebê é um ser que coopera e para isso necessita de tempo e espaço para as ações que ocorrem dentro da instituição, de modo particular nas ações de cuidado que sempre foram tão desvalorizadas, me permitiu visualizar o quanto assegurar tempo para o bebê cooperar é necessário no processo de desenvolvimento da personalidade dos pequeninos. Por essa razão, a flexibilização da rotina é necessária para que o planejamento das ações desenvolvidas possa atender às necessidades e potencialidades do bebê. Entretanto, ainda que a rotina não tenha sofrido alterações, o acesso à informação mobilizou-me para reorganizar a situação de banho. Organizei o banheiro com vasilhas, bacias, brinquedos de borracha, bem como a sala de referência para que os bebês pudessem brincar enquanto aguardavam sua vez para tomar banho. Com essa pequena mudança, enquanto alguns se envolviam na exploração dos objetos seja no banheiro ou [sic] na sala, eu conseguia dedicar mais tempo para o contato individual, bem como dar tempo para o bebê participar da ação que está sendo realizada com ele e não sobre ele. Essa pequena mudança se traduziu em risos e esguichos de água para o ar, mãozinhas deslizando no corpo ensaboado e o total relaxamento no momento das trocas, sem falar nos diálogos entre eles por meio do olhar, toque, expressões faciais, balbucio e até tentativas de emissão de palavras. Essas reações são bem distintas daquelas que eram tão frequentes no momento do banho como susto com a água no corpo e a rapidez das mãos do professor, bem como o corpo tenso sobre o trocador, possivelmente pela insegurança que o momento causa ao bebê" (registro PB).

A análise dos registros revela o lugar que a formação ocupa na construção da profissionalidade para o exercício da docência com e para bebês. Percebe-se que apesar da creche ainda está organizada para atender o bebê a partir de uma visão biológica, pois o que predomina são rotinas institucionalizadas destinadas ao atendimento de suas necessidades físicas, como: trocar as fraldas, alimentar, auxiliar no sono, organizar a sala, etc., as professoras, ao serem afetadas pelo processo formativo, realizaram deslocamentos de modo a favorecer no contexto da creche, espaços de desenvolvimento dos pequeninos, indicando a sua compreensão do bebê enquanto ser social. Assim, o respeito ao tempo do bebê exigiu uma lógica de organização da rotina em que as ações passaram a ser guiadas pelo bebê e não pela rotina institucional. 
Desse modo, o processo formativo passou a ocupar centralidade na docência dessas professoras, pois muitos adultos imersos no cotidiano da creche com rotinas institucionalizadas, relacionam-se, ano após anos, com diversos bebês, e não conseguem perceber o quanto precisam aprender sobre eles para entender quem são e como se expressam. Em decorrência, se relacionam com os pequeninos como se estes fossem objetos que requerem apenas higiene e alimentação.

A partir da compreensão de bebê como ser potente, a docência com e para eles, assume outro lugar e a professora descobre o quanto o trabalho que realiza em situações aparentemente menos importantes, como as situações de cuidado, passam a ter centralidade no processo educativo dos pequeninos, particularmente pelo fato de que as relações estabelecidas entre adulto e bebê exercem uma importância singular na formação da identidade individual e coletiva dos pequeninos.

Nessa perspectiva, as ações de cuidado não são sinônimas de ações mecânicas de higiene e de alimentação. Ao contrário, Sabbag (2017) ressalta a necessidade de evidenciar essas ações como potência, em virtude da riqueza de encontros e trocas que os momentos de cuidado oportunizam. Silva (2018), destaca que ao considerar essa característica da docência como potência haverá uma melhor compreensão da importância destas demandas de contato corporal, de afago das professoras, de vínculo afetivo para o desenvolvimento social e cultural dos bebês. Seguindo este pensamento, Duarte (2012), destaca que as situações de cuidado são extremamente educativas pela troca de gestos, olhares, toques, os quais são fundamentais para o processo de humanização desse chegante ao mundo, com a sua singularidade e pluralidade.

Conhecer quem é o bebê e a profissionalidade da docência com e para eles foi fundamental para as professoras promoverem mudanças na organização do tempo e espaço, a fim de assegurar o tempo para a manifestação do bebê e escuta e compreensão dele. Para tanto, olhar para o bebê como ser potente, que se utiliza de formas de comunicação distintas daquelas usadas pelos adultos, desafiou as professoras a experimentarem 
novas formas de se relacionarem com eles, de responder as suas necessidades. Assim, essa compreensão de bebê potente transbordou para a construção de relações seguras, onde o respeito as singularidades do bebê foram (re)orientadoras da prática docente.

\section{CONCLUSÃO}

A análise desses registros permite-nos concluir o quanto a formação na perspectiva dialógica, ao possibilitar a interlocução e valorização das vozes das participantes, assegurou a manifestação das reflexões das professoras. Estas, muitas vezes, permeadas de angústias e dúvidas em decorrência das condições que são dadas aos bebês e a elas no espaço da instituição, mas também em virtude de elas constatarem o que ainda não sabem, ou que acham saber, pois estas constatações exigiram das docentes desaprenderem o que antes consideravam verdades. Mas, esse processo, acima de tudo, provocou desejo de produzir novos saberes tão necessários para que alguns deslocamentos fossem realizados no cotidiano da creche.

Nesse sentido, o processo formativo permeado pela ação e reflexão, para além do domínio de conhecimentos ou de conteúdos, colaborou com a construção de posicionamento reflexivo que se traduziu em ações e relações interpessoais, o que exigiu das professoras ultrapassar a si mesma e colocar-se rumo ao outro, seja ele o bebê ou o adulto, em busca da superação de limites e construção de outras possibilidades de ser docente de bebês.

Essa constatação possibilita refletir sobre os modelos de formação de professores caracterizados pela transmissão de conhecimentos científicos para serem utilizados pelo professor. Como estes nem sempre fazem sentido no cotidiano da instituição, muitas vezes, o que se percebe é a resistência de muitos professores sob o argumento "a teoria é uma coisa, mas a prática é outra", e pouco impacta no cotidiano da escola.

Apesar de esses modelos de formação ainda serem recorrentes, sabese que a formação é um processo constante de ir e vir, de construção, reconstrução e de desconstrução que envolve diálogos interiores, os quais 
permitem aos sujeitos se constituírem e contribuírem com o processo de constituição do outro enquanto profissionais. Essas reflexões fortalecem a compreensão de que, para o conhecimento científico produzido sobre bebê e a docência com e para eles contribua na transformação da creche enquanto espaço de desenvolvimento, é necessário repensar as práticas de formação dos professores.

Diante da compreensão de formação docente enquanto processo contínuo de ação e reflexão, o qual articula as experiências do cotidiano com concepções teóricas, é necessário trabalhar na construção de práticas de formação que assegurem espaços, a fim de os saberes dos professores articulados com o conhecimento científico sejam objeto de discussão e reflexão. Portanto, esse trabalho deve se pautar no diálogo, enquanto ato coletivo, envolvendo outros sujeitos. É uma possibilidade de o professor encantar-se com sua prática e assim motivar-se para construir as mudanças necessárias no cotidiano.

\section{REFERÊNCIAS}

BARBOSA, M. C. S.; FOCHI, P. S. O desafio da pesquisa com bebês e crianças bem pequenas. IX Seminário de Pesquisa em Educação da Região Sul, 2012. Disponível em:

<http://www.ucs.br/etc/conferencias/index.php/anpedsul/9anpedsul/paper /view/1234/318>. Acesso em: mar. 2021.

BARBOSA, M. C. S.; RICHTER, S. R. S. Os bebês interrogam o currículo: as múltiplas linguagens na creche. Revista Educação. Santa Maria, v. 35, n.1, p. 85-96, jan./abr. 2010. Disponível em: < http://www.ufsm.br/revistaeducação>. Acesso em: mar. 2021.

BARBOSA, S.; GUIMARÃES, D. "Cadê a Viviane? Cadê a Ingrid?" - Visibilidade e invisibilidade das crianças na creche. In: KRAMER, S. (Org.). Retratos de um desafio: crianças e adultos na educação infantil. São Paulo: Ática, 2009.

CASTELLI, C. M.; MOTA, M. R. A. A complexidade de ser bebê: reflexões acerca de sua visibilidade nas creches e nas pesquisas. Revista zero a seis. V. 15, n. 28, p. 46-65, 2013.

DUARTE, F. Professoras de bebês: As dimensões educativas que constituem a especificidade da ação docente. Congresso de Educação Básica:

Aprendizagem e Currículo, 2012. 
FREIRE, P. Pedagogia do Oprimido. 17 ed. Rio de Janeiro: Paz e Terra, 1987.

FREIRE, P. Pedagogia da Autonomia: saberes necessários à prática educativa. São Paulo: Paz e Terra, 1996.

GOTTLIEB, A. Para onde foram os bebês? Em busca de uma antropologia de bebês (e de seus cuidadores). Revista PSICOLOGIA USP. São Paulo, julho/setembro, n. 20(3), p. 313-336, 2009.

GOULART, C. Linguagem, dialogicidade e docência: $O$ processo de formação em atos. Rev. Diálogo Educ., Curitiba, v. 16, n. 49, p. 705-726, jul./set. 2016

HEVESI, K. A participação da criança no cuidado de seu corpo. In: FALK, Judit (org). 2004. Educar os três primeiros anos: a experiência de Lóczy. Araraquara: JM Editora.

INEP, Instituto Nacional de Estudos e Pesquisas Educacionais Anísio Teixeira. Ministério da Educação. Censo Escolar 2016. Notas Estatísticas. Brasília-DF, 2017. Disponível em: <http://portal.mec.gov.br/docman/fevereiro-2017pdf/59931-app-censo-escolar-da-educacao-basica-2016-pdf-1/file>. Acesso em: mar. 2021.

PNAD, Pesquisa Nacional por Amostra de Domicílios. Síntese de indicadores 2015. IBGE, Coordenação de Trabalho e Rendimento. - Rio de Janeiro: IBGE, 2016. Disponível em:

<https://biblioteca.ibge.gov.br/visualizacao/livros/liv98887.pdf>. Acesso em: mar. 2021.

SABBAG, S. "Porque a gente tem um corpo né... mas a gente só lembra do corpo quando ele dói!" A centralidade do corpo adulto nas relações educativas na educação infantil. Dissertação (Mestrado em Educação). Universidade Federal de Santa Catarina. Florianópolis, 2017.

SILVA, I. R. As dinâmicas corporais na docência com bebês. Dissertação (Mestrado em Educação). Universidade do Sul de Santa Catarina. Tubarão, 2018.

TARDIF, M. Saberes docentes e formação profissional. Petrópolis: Vozes, 2002.

Recebido em: 10 de setembro de 2021 .

Aprovado em: 11 de dezembro de 2021 .

Publicado em: 07 de janeiro de 2022. 